\title{
Thyroid Gland Schwannoma
}

National Cancer Institute

\section{Source}

National Cancer Institute. Thyroid Gland Schwannoma. NCI Thesaurus. Code C156340.

A rare schwannoma that arises from the thyroid gland. 